\title{
Maternal Collapse during Caesarean Section: Two Case Reports
}

\author{
Pradhan R, Gurung T, Shrestha S, Basnet U, Sharma KR, Shrestha AB
}

Consultant Anaesthesiologist, Department of Anaesthesiology, Paropakar Maternity and Women's Hospital.

Received: January 2, 2016 ; Accepted: February 22, 2016

Obstetric haemorrhage is the leading cause of maternal collapse in our part of the world. That can result in cardiac arrest. Cardiac arrest during caesarean section is a rare complication which is challenging to both the anaesthesiologists and the obstetricians. Here we are reporting two case series of cardiac arrest during caesarean section following delivery of baby due to haemorrhage. Both the cases revived after prompt and active resuscitation followed by massive blood transfusion.

Keywords: caesarean section; cardiac arrest; maternal collapse

\section{INTR ODUCTION}

Maternal collapse is an event that affects the cardiopulmonary or brain that results in reduced or absent consciousness at any stage in pregnancy and upto six weeks after delivery. ${ }^{1}$ The incidence of cardiac arrest during pregnancy is estimated to be about 1:30,000. ${ }^{2,3}$ Cardiac arrest during caesarean section is a rare complication during pregnancy which is challenging to both the anaesthesiologists and the obstetricians and is difficult to manage if it occurs. Obstetric haemorrhage is the leading cause of maternal collapse in our part of the world. ${ }^{4}$ It is also the leading global cause of maternal death. ${ }^{5}$ Here we are reporting two case series of cardiac arrest during caesarean section following delivery of baby due to massive haemorrhage. Both cases revived after active resuscitation followed by massive blood transfusion.

\section{CASE}

CASE 1

A 24-years-old woman, gravida three and parity one at 40 weeks and one day of gestation presented in emergency department with chief complain of pain abdomen in latent phase of labour. She had no past medical history but had history of caesarean section four years back under subarachnoid block. She was planned for the emergency caesarean section for the scar tenderness of the previous caesarean

\section{CORRESPONDENCE}

Dr. Ritu Pradhan, MD

Consultant Anaesthesiologist

Department of Anaesthesiology

Paropakar Maternity and Women's Hospital

Thapathali, Kathmandu, Nepal

E-mail: ritu_pn@yahoo.com

Mobile no: +977-9841348757 section. During preanaesthetic checkup, she was found pale with haemoglobin of $6.5 \mathrm{gm} / \mathrm{dl}$. There was no abnormality in systemic examination. Her preoperative blood count, coagulation profile, renal function test and liver function test were within normal limits. Four units of whole blood were arranged and cross matched. Her preoperative vitals were: pulse $82 / \mathrm{min}$, blood pressure $114 / 70 \mathrm{mmHg}, \mathrm{SPO}_{2} 98 \%$ in room air. Two wide bore IV accesses were opened in the both arms. She was preloaded with crystalloid in one side and blood transfusion was started in the other side.

Caesarean section was performed under subarachnoid block with $1.8 \mathrm{ml}$ of Inj Bupivacaine heavy $0.5 \%$ and $0.4 \mathrm{ml}$ of preservative free Fentanyl $20 \mathrm{mcg}$. The outcome was single live male baby of $2.8 \mathrm{~kg}$ with Apgar of $6 / 10$ and $8 / 10$. It took around $30 \mathrm{~min}$ for the delivery of the baby due to dense adhesion. Immediately after the delivery of baby, there was profuse blood loss of around $1800 \mathrm{ml}$. Patient developed tachycardia (Heart rate $>140 / \mathrm{min}$ ), shivering and gasping breathing pattern. Blood pressure was $67 / 37 \mathrm{mmHg}$. Endotracheal intubation was done immediately. Patient developed bradycardia and periarrest rhythm. Cardiopulmonary resuscitation was immediately started and Inj Adrenaline $1 \mathrm{mg}$ IV was given. There was return of the spontaneous circulation (ROSC) within 30 seconds with the evidence of continuous wave form seen in the capnograph. The surgery was continued with titrating doses of Ketamine. During intraoperative resuscitation she received two litres of crystalloid and three units of whole blood and one unit of Fresh frozen plasma. After the completion of 
surgery she was kept in electiv mechanical ventilation in Maternal Intensive Care Unit (MICU).

In MICU, central venous cannulation was done and inj Noradrenaline was started at the rate of $5 \mathrm{mcg} /$ min and Dopamine $5 \mathrm{mcg} / \mathrm{kg} / \mathrm{min}$. She was still pale. Her immediate postoperative haemoglobin was $5.5 \mathrm{gm} / \mathrm{dl}$ with prothrombin time of $21 \mathrm{secs}$. She received massive blood transfusion with seven units of whole blood and six units of fresh frozen plasma in the MICU within 24 hours. In the evening she was gradually improving as she was obeying commands and her vitals were maintained as heart rate was between 110 to 120 per minutes and mean arterial pressure between $80-90 \mathrm{mmHg}$ with adequate urine output. She was sedated and paralysed and the mechanical ventilation was continued over the night

The sedative and the paralysing agent were stopped at 6 A.M. the next day. After 2 hours, her Glasgow Coma Scale improved as spontaneous eye opening and she was obeying commands. She was breathing comfortable with the pressure support of $5 \mathrm{cmH}_{2} \mathrm{O}$. Two hours following which the patient had a self extubation. The ionotropes were tapered off and stopped after 2 days.

During postoperative period, psychiatric consultation was done for the delirium and treated. She was discharged on the $16^{\text {th }}$ postoperative day without any neurological deficits.

\section{CASE 2}

A 33-years-old woman gravida two parity one with history of previous caesarean section at term pregnancy was planned for the elective caesarean section for the complete placenta praevia. She had no past medical history but had a history of caesarean section five years back for failed induction. This time caesarean section was done under subarachnoid block. Immediately after the delivery of the baby, there was profuse blood loss due to uterine atony and placenta increta was noted. Suddenly patient became unconscious and immediately developed asystole. Chest compression was immediately started and inj Adrenaline $1 \mathrm{mg}$ IV was given. Endotracheal intubation was done. There was return of spontaneous circulation after about 30 seconds of cardiac arrest with continuous curve of capnograph. The patient received one litre of colloid, three units of whole blood and one unit of fresh frozen plasma during resuscitation. Emergency hysterectomy was undertaken to control the bleeding. The total events starting from the anaesthesia to the completion of surgery was 30 minutes. The patient became conscious at the end of surgery with stable vitals and was extubated on the operation theatre. Inj Dopamine was started and she received two more units of whole blood in MICU. The dopamine was stopped the next day. Her postoperative stay was uneventful and she was discharged on $9^{\text {th }}$ post -operative day without any complication. Her biopsy report also showed placenta increta. This was the case of unpredictable haemorrhage leading to cardiac arrest which was timely managed.

\section{COMMENT}

In this report, we had two cases of maternal cardiac arrest, which were successfully managed because of timely recognition of the problem, effective cardiopulmonary resuscitation and the rapid availability of blood and blood products. In case 1, the risk factor for the cardiac arrest was the preoperative low haemoglobin due to which she could not tolerate the intraoperative massive haemorrhage as well as history of previous caesarean section which causes dense adhesion. In case 2, there was also a history of previous caesarean section that might be the reason for placenta adherence. The massive haemorrhage was unpredictable leading to cardiac arrest. In both the cases the maternal collapse occurred following delivery of the baby so there were no issues for the perimortem caesarean section.

The cause of cardiac arrest in both the cases was hypovolaemic shock. The differential diagnoses were amniotic fluid embolism, air embolism, thromboembolism and high spinal block. In both the cases, there was no history and clinical finding suggestive of thromboembolic phenomenon and there was no murmur on auscultation of heart, ruled out air embolism. Amniotic fluid embolism is less likely as it is the diagnosis of exclusion. The acute onset of dyspnoea, signs of pulmonary congestion and severe coagulopathy were absent in both the cases which rule out the amniotic fluid embolism.

Obstetric haemorrhage is responsible for an estimated $25 \%$ of maternal death in pregnancy. ${ }^{6}$ Although obstetric patient is physiologically well prepared for the haemorrhage due to changes of pregnancy, there is also great risk of extensive blood loss from the gravid uterus. Pregnancy induces a hypervolaemic state and a pregnant patient can experience massive 
blood loss before manifesting any significant changes in vital signs. Failure to recognise and treat the haemorrhage early can result in loss of both the foetus and mother. ${ }^{7}$ Rapid assessment and initiation of appropriate resuscitative measure can greatly improve the prognosis. ${ }^{8}$

There are case reports of cardiac arrest during caesarean section. By Susan et al Bezold Jarisch reflex was the most likely cause of cardiac arrest. ${ }^{9}$ In the other case, the possible cause was amniotic fluid embolism. ${ }^{10}$ Bezold Jarisch reflex is a type of cardioinhibitory type of cardiovascular reflex which causes inhibition of sympathetic outflow coupled with bradycardia, peripheral vasodilation and hypotension. ${ }^{11}$ This change is triggered by reduced cardiac venous return as well as through affective mechanism such as pain or fear. This response may occur during regional anaesthesia, haemorrhage or inferior venacava compression in pregnancy and these factors are additive when combined. ${ }^{12}$ This can be the mechanism of cardiac arrest in the both the cases due to massive haemorrhage.

The effective management of these types of obstetric emergencies depends on the skill and support of multidisciplinary team of obstetrician, anaesthesiologist, intensivist, haematologist and trained nursing staffs. Cardiac arrest during caesarean section is an uncommon complication which is difficult to manage. Hence adequate planning, preparation, emergency drills and hospital protocols are important for this type of situation.

\section{CONCLUSION}

Obstetric haemorrhage is unpredictable which can be life threatening. Immediate resuscitation by the trained personnel can save the lives. Both the patients were discharged without any neurological deficits because they immediately received effective cardiopulmonary resuscitation and volume resuscitation which might have reduced the hypoxic brain injury. The vigilant assessment and monitoring of the patient and preparedness are important.

\section{REFERENCES}

1. RCOG report on Maternal collapse in Pregnancy and Pueperium. [Cited on ] Available from https://www.rcog. org.uk/globalassets/documents/guidelines/gtg56.pdf.

2. Mallampalli A, Powner DJ, Gardner MO. Cardiopulmonary resuscitation and somatic support of the pregnant patient. Crit Care Clin. 2004;20: 747-61.

3. Morris S, Stacey M. Resuscitation in pregnancy. BMJ. 2003;327: 1277-9.

4. Bhandari TR, Dangal G. Maternal Mortality: Paradigm shift in Nepal. Nepal J Obstet Gynaecol. 2012;7: 3-8.

5. WHO. Make every mother and child count. World Health Organisation. Geneva. 2005.

6. Martin SR, Foley MR. Intensive care in obstetrics: an evidence-based review. Am J Obstet Gynecol. 2006; 195: 673 89.
7. Campbell TA, Sanson TG. Cardiac arrest and Pregnancy. J Emerg Trauma Shock. 2009;2: 34-42.

8. Crochetiere C. Obstetric emergencies. Anaesthesiol Clin North America. 2003;21: 111-25.

9. Van Liempt SW, Stoecklein K, Tjiong MY, Schwarte LA, de Groot CJ, Teunissen PW. Essentials in cardiac arrest during caesarean section. Clin Pract. 2015;5: 668.

10. Mahshid N, Ahmad S, Nahid M, Afshin F. Sudden cardiac arrest during cesarean section - a possible case of amniotic fluid embolism. Middle East J Anaesthesiol. 2009;20: 315-7.

11. Campagna JA, Carter C. Clinical relevance of the Bezold Jarisch reflex. Anaesthesiology. 2003;98:1250-60.

12. Kinsella SM, Tuckey JP. Perioperative bradycardia and asystole : relationship to vasovagal syncope and the BezoldJarisch reflex. Br J Anaesth. 2001;86: 859-68. 